EPJ Web of Conferences 12, 04002 (2011)

DOI: $10.1051 /$ epjconf/20111204002

(C) Owned by the authors, published by EDP Sciences, 2011

\title{
Prediction of prestressing losses for long term operation of nuclear reactor buildings
}

\author{
I. Cornish-Bowdena , G. Thillard and B. Capra \\ Oxand SA, 49 Avenue Franklin Roosevelt, 77210 Avon, France
}

\begin{abstract}
Prestressed concrete is used in nuclear reactor buildings to guarantee containment and structural integrity in case of an accident. Monitoring and operating experience over 40 years has shown that prestressing losses can be much greater than the design estimation based on the usual standard laws. A method was developed to determine the realistic residual prestress level in structures, in particular for those where no embedded instrumentation was installed, taking into account in situ measurement results rather than design characteristics. The results can enable the owner to justify extending the lifespan while guaranteeing adequate safety and to define and plan adequate maintenance actions.
\end{abstract}

\section{INTRODUCTION}

Producers of nuclear power operate civil-engineering infrastructure which they must maintain. As long as existing structures are in their "youth" (slow-to-moderate ageing phase), most of the damage that appears is minor, and can be handled with a curative strategy, and maintenance budgets can be planned on the basis of recurrent costs.

The ageing of structures results in a sharp increase in degradation and in corresponding maintenance costs. Furthermore, as budgets become more stringent it becomes impossible to refurbish all of the various structures. It is therefore important to anticipate and evaluate the ageing of infrastructure to quantify maintenance needs appropriately, in particular for nuclear power plants for which operating license renewal is desired.

The most recent nuclear reactor buildings are designed with a prestressed concrete containment shell, which has various functions such as shielding (to protect the environment from radioactive emissions), and providing a structural pressure barrier (to guarantee containment and structural integrity of the structure in an emergency). The prestressing in these kinds of structures is both vertical and circumferential, inducing prestressing losses over time which are difficult to predict and estimate. In particular, experience of many reactor containment buildings over 40 years of operation and monitoring has shown that prestressing losses can be much greater than the design estimation based on the usual standard laws, thus reducing the actual service lifetimes of the structures. This ageing mechanism may become critical when owners hope to extend the lifespans of their civil works.

French construction practice, as well as in many other European countries, is to use cement grouting for the majority of prestressing systems. This is an effective means to protect tendons against corrosion, but it prevents direct measurements of the residual prestress and the replacement or retensioning of tendons. Moreover, owners of concrete structures often underestimate the potential ageing of reinforced

a e-mail: isadora. cornish@oxand. com

This is an Open Access article distributed under the terms of the Creative Commons Attribution-Noncommercial License 3.0, which permits unrestricted use, distribution, and reproduction in any noncommercial medium, provided the original work is properly cited. 


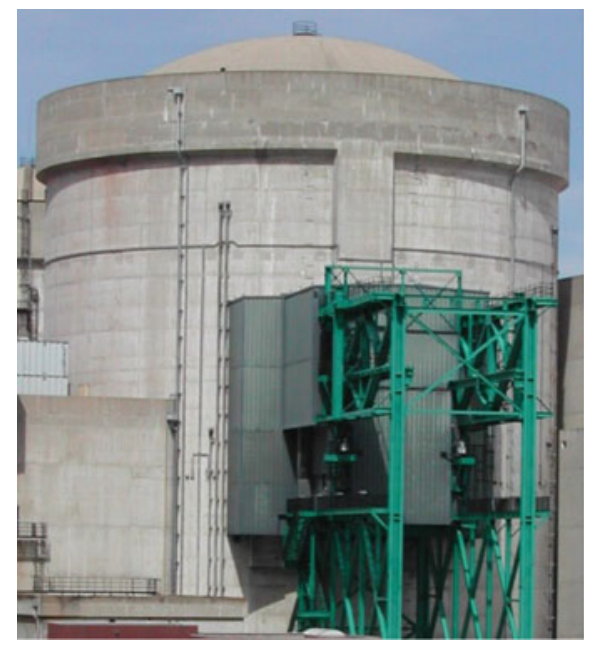

Figure 1. Nuclear Containment building, Cruas, France, Photograph by the authors.

concrete, and there may have been little monitoring of the structure during its lifetime, or processing of monitoring data to assess the residual lifespan.

This article presents a method developed to determine the residual prestress level in structures, in particular for those where no embedded instrumentation is installed. It was applied to various prestressed civil structures to evaluate their residual lifespan.

\section{RISK ANALYSIS: IDENTIFICATION OF RISKS IMPACTING LIFESPAN}

A nuclear reactor containment building is a costly investment which leads owners to seek means of increasing their return on investment. Ensuring that the plant operates for its full expected life time, or even extending the life time, is therefore very important. In response to this need, which is shared by most civil engineering infrastructure owners, we have developed a methodology based on risk analysis and applied it to various biaxially prestressed structures such as containment buildings and liquefied natural gas (LNG) storage tanks.

Risk analysis has been used for several years in industry but more recently for advising owners on infrastructure management. Our experience feedback has proven it to be a well adapted, robust and well-understood methodology for optimising infrastructure management.

The methodology used in this article is based on the FMECA (Failure Mode Effect and Criticality Analysis) method applied to the containment building as well as all auxiliary buildings and structures. It begins with a functional analysis of the system (integrating all its structural components and equipment), goes over a thorough identification and quantification of the potential failure modes and ends with a prioritisation of appropriate actions.

Compared to more traditional management methods, risk-based management enables owners to take into account their own stakes such as safety, costs (available budget), availability, respect of the environment, security, etc. Some risks may have more impact on a stake than others, and risk-based management allows risk treatment actions for a given stake to be favoured. The main aim of risk-based management is to guarantee that owners fulfil their objectives. It enables (1) anticipation of performance discrepancies, (2) definition of a suitable action plan for risk treatment, (3) execution of this action plan and (4) control of its efficiency.

Identification and quantification of potential failure modes takes into account the effects of ageing, thanks to in situ data. These enable us to assess the ageing level of the structure and to determine a realistic prediction of its evolution. This prediction will then confirm, or not, whether the performance 
objectives will be met or if treatment is required and when. At a given moment, deciding between pursuing operation with maintenance costs or reinvestment in a new structure will depend on the residual risk level associated with operation considering possible maintenance actions, and on the end of life criteria. The most critical risks - which will favour one decision or the other - are most often related to the structure's ageing mechanisms.

Causes of risks with an impact on lifetime can be construction defects, ageing mechanisms, or loading increases. For example, evolution of an ageing mechanism responsible for a critical failure may lead to the end of the life of the structure. To be able to control these risks, it is therefore important to identify them.

One of the main ageing mechanisms with an impact on mechanical behaviour, and therefore on life time, appeared after the risk analysis to be prestressing losses that could lead to a decrease of the compressive stress in the concrete wall to a level below a predefined minimum linked to safety requirements. This article will focus on this particular ageing mechanism.

Another ageing mechanism which impacts mechanical behaviour is corrosion of the rebars and prestressing tendons. The structures which are located by the sea are particularly vulnerable to environmental aggressions. Once corrosion starts, it leads to a progressive decrease in the rebar section. An important decrease will impact on the mechanical resistance of the structure and may require extensive repairs, expensive in terms of both time and money. Corrosion of the different structures and components within a given structure was compared by calculating the evolution of corrosion thanks to numerical simulations and the impact of this corrosion on the structure. These calculations took into account for each component then environmental conditions, the presence of existing defects (cracks), the real concrete cover around the rebars and the concrete characteristics. Risk analysis enabled to compare the corrosion of the various components, to determine where it was more critical, and what kind of repair will then be necessary for each part of the structure and when, varying from light maintenance or surveillance to heavy works (e.g., rebar replacement).

In particular, risk analysis enabled to highlight ageing mechanisms which are sometimes underestimated because they don't cause immediate visible defects but which may impact lifetime, in relation to visible defects which tend to be repaired quickly although they may not be critical.

\section{PRESTRESSING LOSSES}

\subsection{Prestressing characteristics}

Concrete as a material is more or less sensitive to the effects of creep, depending on the type of concrete used, the intensity of applied loads, and the age of loading. The effects of this creep sensitivity are an increase in deformation over time, which in some cases may have important consequences.

In the case of containment buildings, concrete creep will result in loss of prestress, which will lead to the decrease of compressive stresses in the concrete walls. If the remaining compression decreases below the prescribed minimum threshold, containment is not ensured and the structure no longer fulfils its intended function.

The reactor containment buildings are particular in the sense that they are vertically and horizontally prestressed. This biaxial load will result in different creep behaviour to that given by the usual laws, which are generally derived from uniaxial tests.

So, during the lifetime of prestressed structures, the tension in the tendons decreases due to delayed phenomena in materials (concrete shrinkage and creep, steel relaxation). These prestressing losses are estimated during design using standard rules. When the structures where designed, the prestress losses were based on empirical estimations or on data from test results which didn't take into account variable loads, length changes, or interaction between steel relaxation and concrete creep, leading to considerable error [1]. The last 40 years have been dedicated to developing more accurate laws and methods to calculate prestress losses. Operating experience and monitoring of many reactor containment 


\section{EPJ Web of Conferences}

buildings over 40 years shows that concrete creep measured on site can be much higher than the initial estimation, and that prestressing losses can be very different from what was predicted during design. Sometimes these losses are lower than predicted, and thus acceptable, in particular in the case when the initial tensioning was done at late concrete age [2]. However, losses may also be higher than predicted, reducing the safety margin of the structure. Structures stressed with horizontal and vertical tendons have been proved to be more sensitive to this phenomenon. This ageing mechanism may become critical when owners hope for a lifespan extension of their structures.

The main role of prestressing tendons is to ensure the resistance and leaktightness of the structure, in particular in the case of accidental loads (internal overpressure, flood barrier, etc.). These accidents, though rare, may occur during operation and it is therefore essential to estimate the residual prestressing level.

Estimating the residual prestressing tendon tension and its future evolution is especially important in the case of cement-grouted tendons, as the tendons cannot be replaced or tightened. Cement grouting is an effective means for protecting tendons against corrosion, but prevents direct measurements of the residual prestress, and the replacement or retensioning of tendons. Moreover, owners of concrete structures often underestimate the potential ageing of reinforced concrete, and there may have been little monitoring of the structure during its lifetime, or processing of monitoring data to assess the residual lifespan.

Realistic evaluations of prestressing loss were carried out for concrete tanks belonging to the client, using finite element simulations taking into account a biaxial creep model $[3,4]$.

\subsection{The real characteristics of structures}

The calculation uses in situ measurement results rather than design characteristics of the structure, in order to take into account not only possible construction defects or gaps, but also the real characteristics of the concrete, which may be better than designed, thus enabling safety margins to be optimised.

The required input data are as follows:

- Geometrical data,

- Layout of reinforcing rebars,

- Prestressing tendon plans and initial values of prestress,

- Characteristics of concrete depending on temperature,

- Permanent thermal gradients,

- Water saturation conditions,

- Design calculation documents,

- Real composition of the concrete in the structure.

\subsection{Creep and shrinkage behaviour}

Concrete creep is also related to the loading conditions of the structure: concrete age at loading, intensity of loading, etc. Figure 2 below illustrates the delayed behaviour of concrete under uniaxial loading.

For containment buildings the loading is biaxial (vertical and horizontal prestressing), and the model used to determine the deformations must consider the possible interactions between the directions of loading (Poisson's creep ratio). The creep and shrinkage that occur on the structure are estimated by means of feedback from field experience on similar concretes and specific evolution models for bidimensional creep [4].

At present there is no universal method which provides a creep law based on the composition of concrete. However, there are numerous studies on its influence on the amplitude and kinetics of creep (experimental results, regulatory models, analytical equations, etc.). Various studies [6-9] were able to identify and characterize the importance of specific composition parameters on the evolution of concrete creep: water / binder ratio, aggregates, cement type and additives. The kinetics and magnitude 


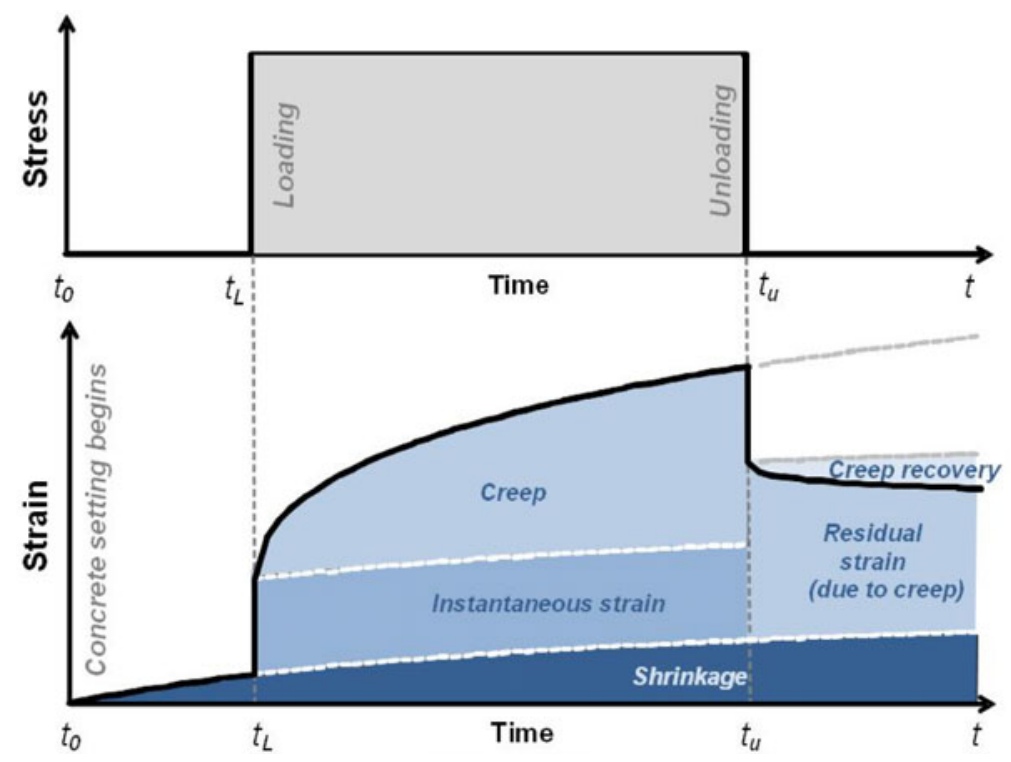

Figure 2. Conventional distribution of strains during uniaxial loading [5].

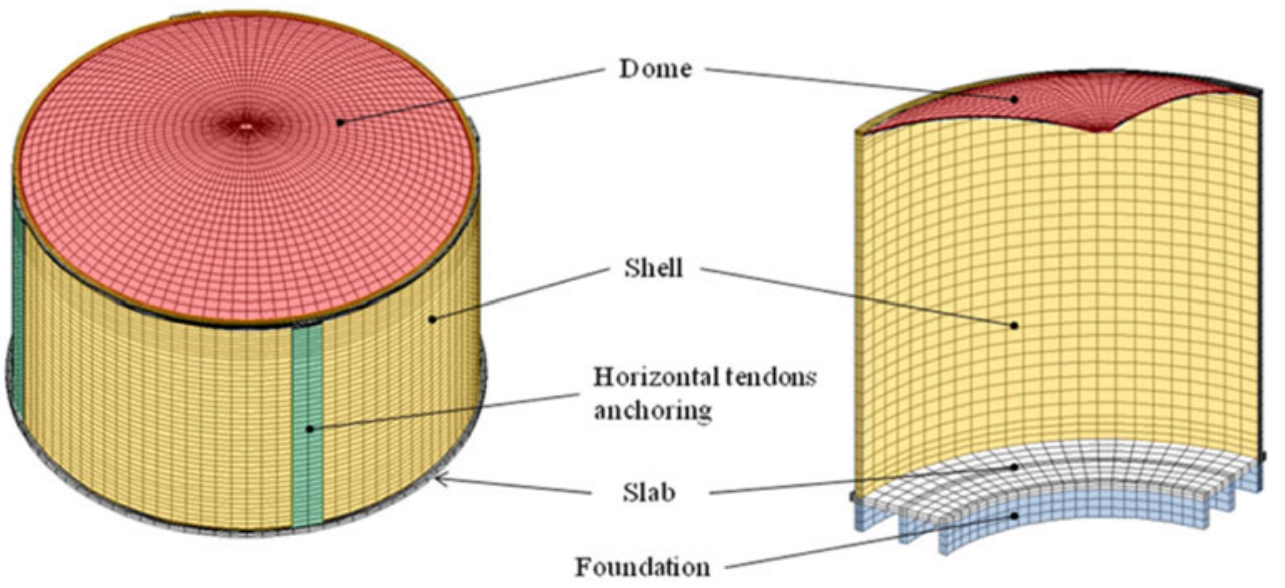

Figure 3. Example of concrete mesh (liquefied gas storage tank).

of creep also depend on environmental conditions: temperature, humidity, age and level of loading. These different analyses have enabled the development of some creep laws which need to be calibrated based on experimental results [8, 10-13].

We defined a biaxial creep model which was as representative as possible of the material of the structure based on the available data on the composition of the concrete and drying conditions of the structure. The model was based on a literature review and an existing database [14]. The creep laws obtained at the end of this study were then compared with those given in current construction codes.

\subsection{Calculation of prestressing losses}

Thanks to this estimation, a realistic calculation of the resistance of the structure submitted to various stresses can be made using a three-dimensional model (Figure 3). On this basis, the owner can justify 


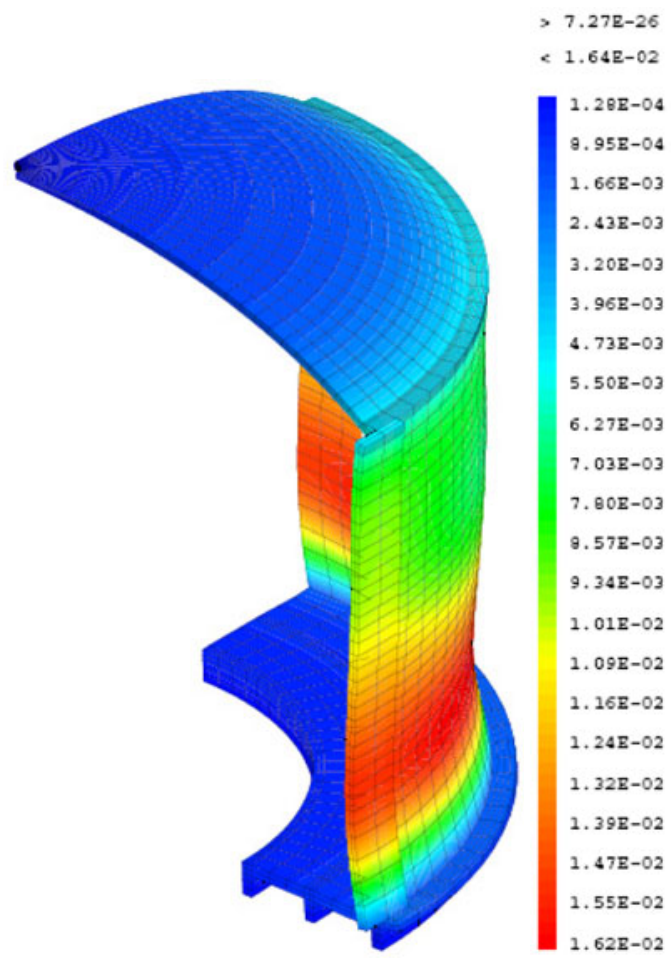

Figure 4. Radial displacements due to prestressing (m).

a lifespan extension while guaranteeing adequate safety, or adapt operating conditions to prevent particular strains.

Prestressing the structure will cause it to experience various strains in time. Figure 4 is an example of the structures' deformation. This deformation is due on the one hand to the vertical prestressing which "shrinks" the structure vertically, and on the other hand to the horizontal prestressing which constricts the cylinder towards its centre. The zone of maximum horizontal displacement (in red on the figure) is influenced by the distribution of the horizontal tendons in the structure (the tendon density decreased with the height of the shell).

From the creep law identified during the first phase, the current loss of prestress due to creep, together with the expected losses in the future, in this case in 2040, can be estimated by means of a finite element calculation. Creep is modelled using the finite element software Code_Aster ® [15-18] which includes several models for concrete creep:

1- The BAZANT model [16], based on the work of Bazant and Chern [19, 20] which simulates the creep due to changes of humidity of the material;

2- The GRANGER model, based on the work of Granger [8], that allows adjustment of the evolution of the creep law for uniaxial loading and variable conditions of temperature and humidity;

3- The UMLV model [18], based on the work of Benboudjema [4], developed for simulating creep under biaxial loading and variable conditions of temperature and humidity.

The choice of the creep model best suited to the structure is decided after consulting experts, and is based on the characteristics of the studied structures and materials. The UMLV model was used to calculate the basic creep since it is the only model that takes into account biaxial loading and it is based on the BAZANT model for drying creep. 


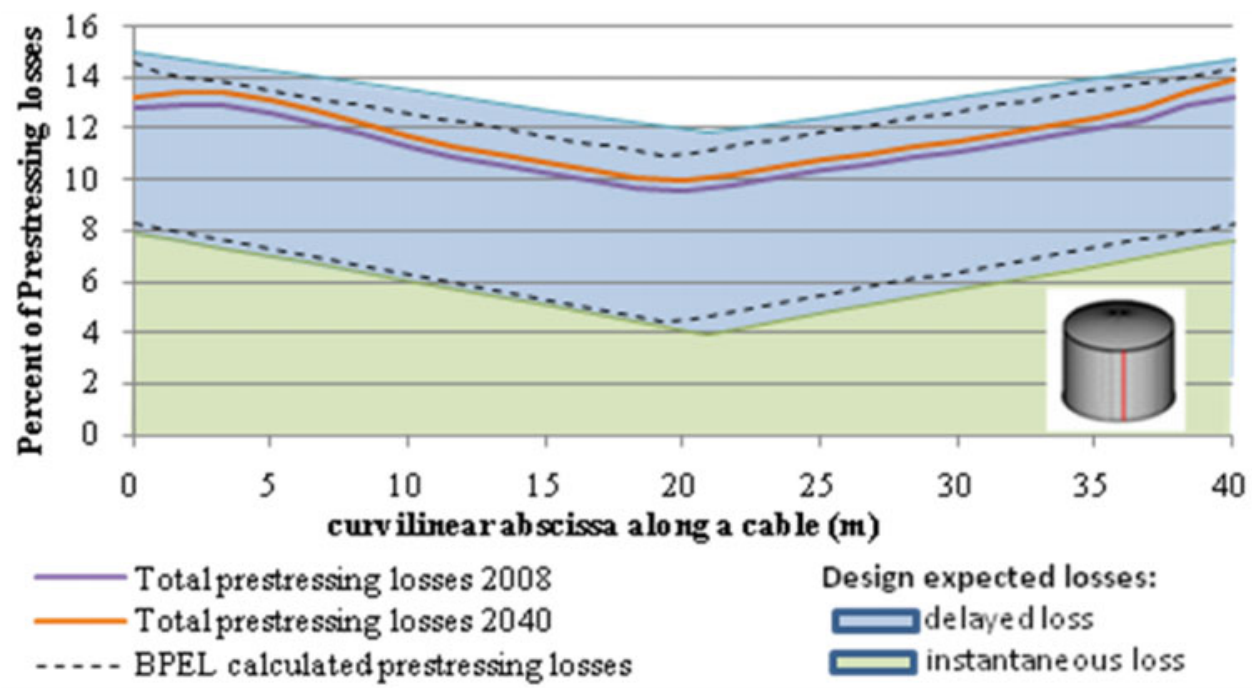

Figure 5. Comparison of design, BPEL and "realistic" prestressing losses for the vertical tendons.

The considered loading cases include the following:

- Weight of the structure and equipment (average annual loading);

- Prestressing;

- Permanent thermal gradients (average annual loading);

- Internal pressure.

The models incorporate the influential parameters of temperature and relative humidity, and consider linear elastic behaviour for steel and nonlinear behaviour for concrete (elasto-plastic law with negative linear hardening - "BETON_ECRO_LINE” model in Code_Aster ®).

Figures 5 and 6 show the difference between:

- prestressing losses estimated during design (almost 40 years ago),

- prestressing losses calculated with the usual standard laws (which did not exist at the time of design): in this case the French BPEL, 1999 Edition, and

- a realistic calculation of the prestresing losses with the UMLV creep model.

The residual prestressing losses between 2008 and 2040 are approximately $1 \%$.

For the vertical prestress, the losses appear to be lower than what was estimated during design, and so are acceptable.

For the horizontal prestress, the design loss estimation was lower than the losses which would have been calculated with the current standard laws (for uniaxial prestress) and both of these losses are underestimated by approximately $15 \%$ in relation to the realistic losses for bi-axial prestress, in particular at the level of the anchorage. However, as the horizontal tendons are anchored $90^{\circ}$ apart, this local underestimation becomes lower when considering all the cables.

\subsection{Impact of prestressing losses}

Once the prestressing losses have been determined, the acceptability of the results has to be demonstrated by checking that the required minimum compression is still applied during design-basis events.

One of the design-basis events leads to simulating an accidental overpressure in the containment building. The previous calculations of prestress loss due to creep are performed again, this time considering the accidental overpressure at two moments in time: 2008 and 2040. Figures 7 and 8 give an example of the results that were obtained in the specific case of an LNG storage tank. 
EPJ Web of Conferences

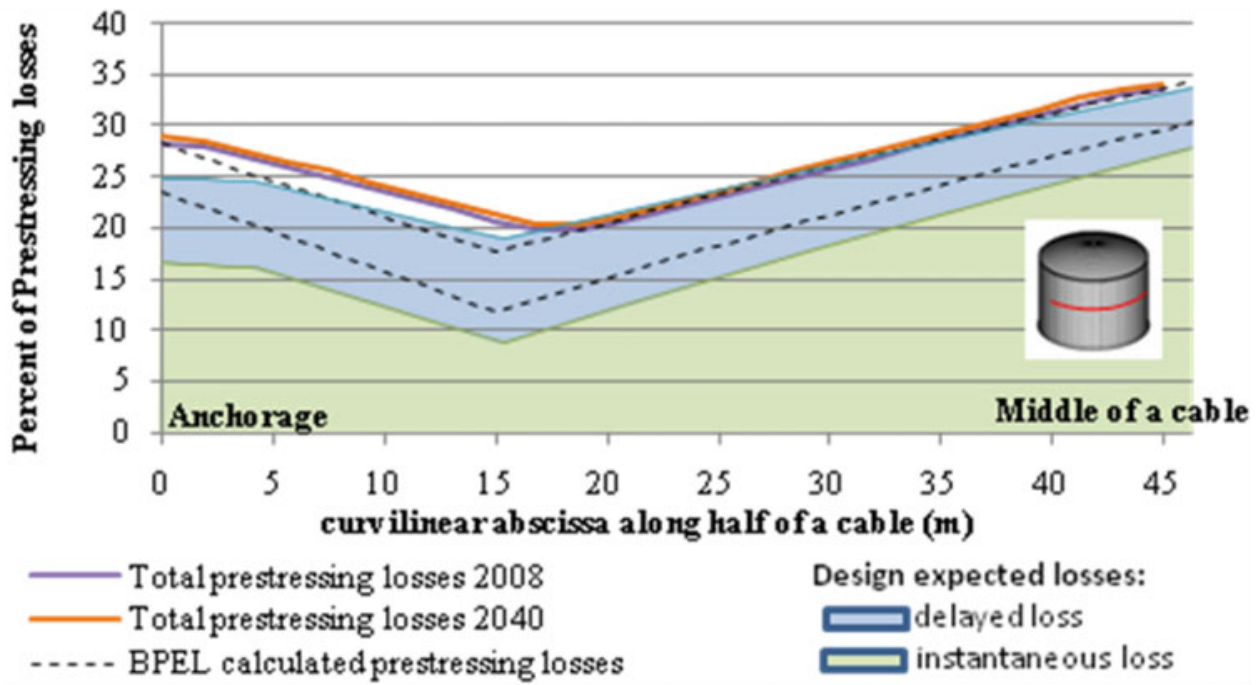

Figure 6. Comparison of design, BPEL and "realistic" prestressing losses for the horizontal tendons.

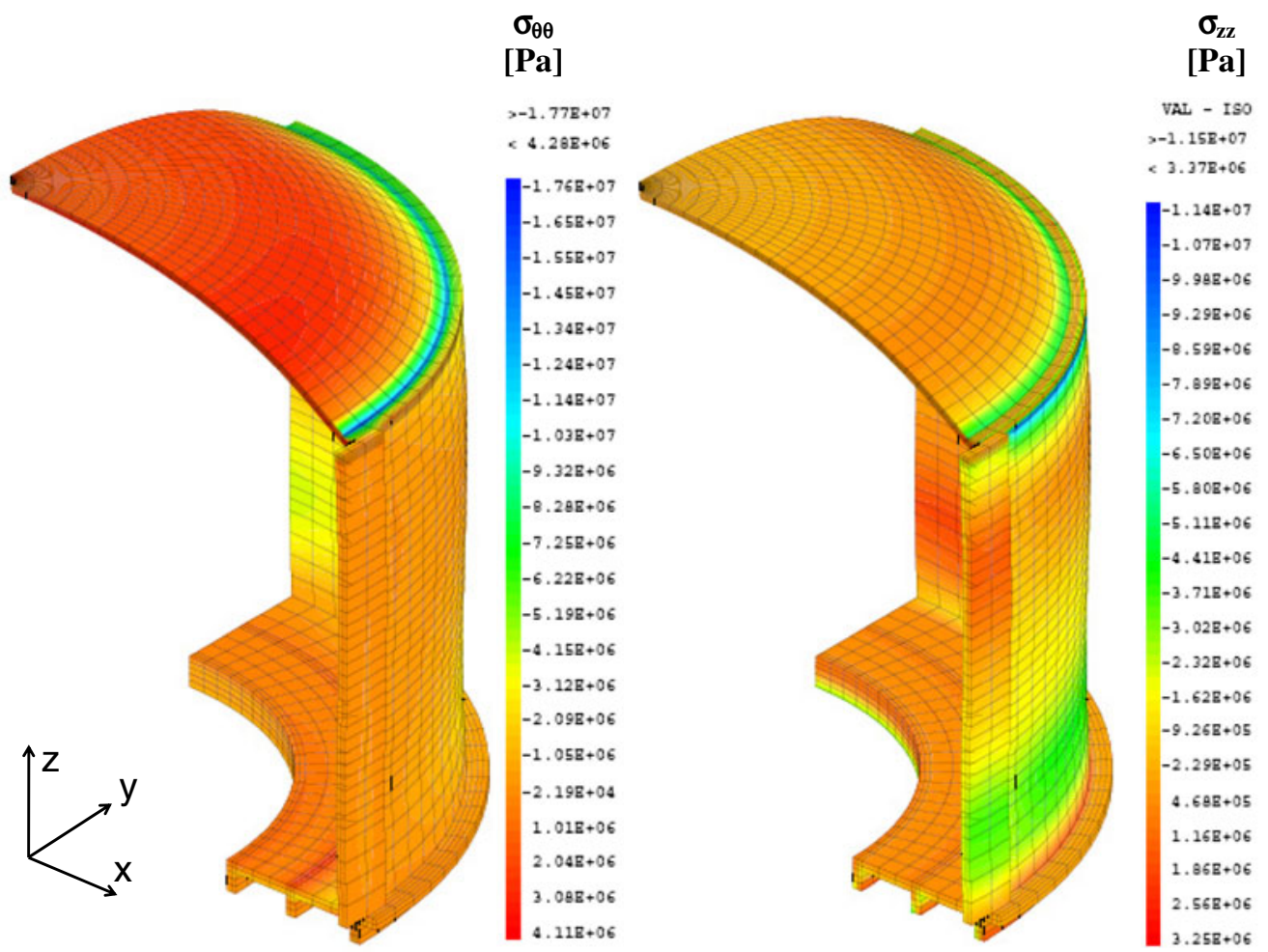

Figure 7. Principal stress fields during an internal overpressure considering prestressing losses (LNG storage tank) positive values $=$ traction ; negative values $=$ compression . 

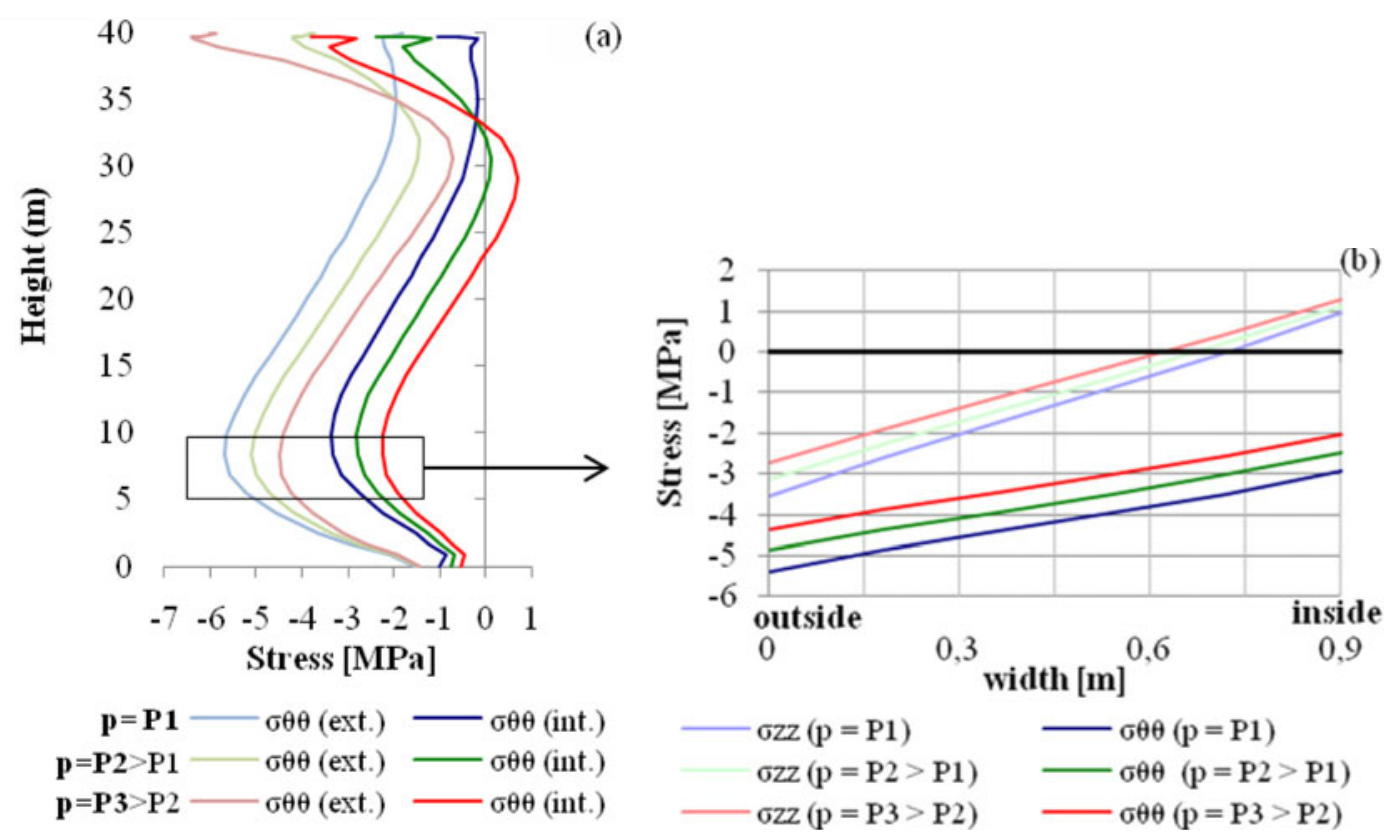

Figure 8. Stress levels in the structure (a) over the height for the intrados and extrados (b) over the width at a particular height.

The numerical simulations were used to determine the level of internal pressure leading to the following results:

1- No compression in the concrete,

2- Plastic deformation of steel reinforcing rebars,

3- Plastic deformation of prestressing tendons (breaking of tendon considered as fragile).

These simulations enable the mechanical resistance of the structure when submitted to normal and accidental loadings to be checked, and the residual lifetime aim to be confirmed. The criticality of the related failure mode can then be assessed.

\section{IDENTIFICATION OF APPROPRIATE MAINTENANCE ACTIONS}

The risk evaluation phase highlighted the risks which may have an impact on the residual life time and which require remedial actions.

An action plan was proposed based on the risk ranking and technical feasibility of the actions, and their impact on the availability of the plant; the recommended actions are defined to manage the most critical risks. These actions are then planned depending on whether the risks were already critical, and thus urgent, or not, and on the results of the prediction.

For the components which had critical and very critical risks (e.g. loss of mechanical strength due to corrosion) preventive treatment and/or heavy works (e.g.: replacement, repair, reinforcement) were recommended. The significant risks (e.g. loss of containment due to prestressing loss) were dealt with by survey treatment (inspections, monitoring, etc.). When further investigation was recommended, instructions as to the most suitable way to proceed were supplied (with highlighting of non-destructive tests). Emphasis was put on missing data, to help reduce uncertainties of failure mode assessment.

The action plan fulfils the owner's need to anticipate his maintenance budget for the long term as well as the unavailability periods necessary for maintenance. These unavailability periods may then be scheduled to reduce their impact on the owner's production objectives. 
EPJ Web of Conferences

\section{CONCLUSION}

While carrying out a global risk analysis of a biaxially prestressed structure similar to a nuclear reactor building, prestressing losses were found to be a major cause for failure modes which could jeopardize the structure's lifespan. The lack of sufficient monitoring devices meant there were many uncertainties in the residual prestress level and in the adequacy of this level for guaranteeing the absence of impact on the intended functions of the structure, in particular during an accidental overpressure.

A realistic prestress level was then calculated with a three dimensional finite element model taking into account creep laws, the real characteristics of the concrete, and experience feedback of creep on similar structures.

The results enabled the acceptable accidental internal limit overpressure for the structure to be calculated and, in this particular case, the absence of impact of the current and expected prestressing losses to be demonstrated. On this basis, the owner was able to justify a lifespan extension while guaranteeing adequate safety.

The authors thank Christophe Baillis from EC2-MS and Farid Benboudjema from LMT Cachan for their contribution to this study.

\section{References}

[1] R.J. Glodowski, J.J. Lorenzetti, A method for predicting prestress losses in a prestressed concrete structure, PCI Journal, March-April 1972, p17-31 (1972)

[2] P. Anderson, Thirty years of measured prestress at Swedish nuclear reactor containments, Nuclear Engineering and Design, 235, Issue 21, p. 2323-2336 (2005)

[3] F. Benboudjema, F. Meftah, J.M. Torrenti, G. Heinfling, A. Sellier, On the prediction of delayed strains for concrete subjected to drying and loading simultaneously, Concreep6 Creep, Shrinkage \& Durability Mechanics of Concrete and other Quasi- Brittle Materials, p. 245-250, M.I.T. Cambridge, USA (2001).

[4] F. Benboudjema, F. Meftah, J.M. Torrenti, G. Heinfling, A. Sellier, A basic creep model for concrete subjected to multiaxial loads, $4^{\text {th }}$ International Conference on Fracture Mechanics of Concrete and Concrete Structures, Cachan, France, 28-31 Mai 2001, p. 161-168 (2001)

[5] J.P. Ollivier, A. Vichot, La durabilité des bétons, Presse de l'ENPC, pp.167-246 (2008)

[6] J. Baron, R. Sauterey, Le béton hydraulique, connaissance et pratique. Presse de l'Ecole Nationale des Ponts et Chaussées, Paris (1982).

[7] A.M. Neville, W.H. Dilger, J.J. Brooks, Creep of plain and structural concrete, London: Construction Press, 361p. (1983)

[8] L. Granger, Comportement différé du béton dans les enceintes de centrales nucléaires. Analyse et modélisation, Doctoral thesis, Ecole Nationale des Ponts et Chaussées (ENPC), 397p. (1995)

[9] B. Bissonnette, Le fluage en traction: an un aspect important de la problématique des réparations minces en béton, Doctoral thesis, Laval University, Quebec City, Canada, (1996)

[10] Z. P. Bazant, Mathematical modeling of creep and shrinkage of concrete, Material models for Structural Analysis, Chapter 2, In: Bazant Eds - UK : John Wiley \& Sons, Ltd, p 99-215 (1988)

[11] F.J. Ulm, P. Acker, Le point sur le fluage et la recouvrance des bétons, Bulletin du Laboratoire des ponts et Chaussées, p 73-82 (1998)

[12] F. Benboudjema, F. Meftah, J.M. Torrenti, Drying creep: an elasto-plastic approach of the structural effect, $4^{\text {th }}$ International Conference on Fracture Mechanics of Concrete and Concrete Structures, Cachan, France, 28-31 Mai 2001, p. 169-176 (2001). 
AMP 2010

[13] A. Berthollet, Contribution à la modélisation du béton vis-à-vis du vieillissement et de la durabilité : interaction des déformations de fluage et du comportement non-linéaire du matériau, Doctoral thesis, Institut National des Sciences Appliquées de Lyon (INSA), 406p. (2003)

[14] Z. P. Bazant, LI G. H., Comprehensive Database on Concrete Creep and Shrinkage (2008)

[15] G. Debruyne, B. Ciree, EDF-R\&D/AMA / IRSN : Manuel de Référence Code_ASTER - R7.01.12 - Modélisation de la thermo-hydratation, du séchage et du retrait du béton (2005)

[16] J. El Gharib, EDF-R\&D/AMA : Manuel de Référence Code_ASTER - R7.01.05 - Relation de comportement de Bazant pour le fluage de dessiccation intrinsèque du béton (2003)

[17] J.P. Lefebvre, EDF-R\&D/AMA : Manuel d'Utilisation Code_ASTER - U4.43.01 - Opérateur DEFI_MATERIAU, Partie 7 : Comportements spécifiques aux bétons (2008)

[18] Y. Le Pape, EDF-R\&D/MMC : Manuel de Référence Code_ASTER - R7.01.06 - Relation de comportement UMLV pour le fluage propre du béton (2004)

[19] Z. P. Bazant, J.C. Chern, Strain softening with creep and exponential algorithm, Journal of Engineering Mechanics, 111, No.3, p.391-415 (1985)

[20] Z. P. Bazant, J.C. Chern, Concrete creep at variable humidity : constitutive law and mechanism, Matériaux et Constructions/Materials and Structures, 18, No.103, p.1-20 (1985) 